\title{
Measuring student graduateness: reliability and construct validity of the Graduate Skills and Attributes Scale
}

\section{Melinde Coetzee}

Department of Industrial \& Organisational Psychology, University of South Africa, Pretoria, Gauteng, South Africa

This study reports the development and validation of the Graduate Skills and Attributes Scale which was initially administered to a random sample of 272 third-year-level and postgraduate-level, distance-learning higher education students. The data were analysed using exploratory factor analysis. In a second study, the scale was administered to a stratified proportional random sample of 1102 early-career, undergraduate open distance-learning higher education students in the economic and management sciences field. The data were analysed using confirmatory factor and Rasch analyses. The structural validity and reliability of the scale were confirmed by the results. Educators and learning and development practitioners may be able to use the findings in their teaching, learning and assessment design.

Keywords: adult learners; employability; graduate attributes; graduateness; transferable meta-skills and attributes

\section{Introduction}

The current demands of a globalised knowledge-driven economy and rapidly evolving information technology significantly influence the capabilities expected from graduates (Griesel \& Parker, 2009; Kember \& Leung, 2005; Reissner \& Watson, 2010) in the pursuit of their careers. Recognising the increasing demand for employable graduates (Lo, 2011; Pityana, 2009; Tomlinson, 2007), higher education academics realise the importance of imparting the skills and attributes graduates need to be competent in making sustained positive contributions to society, their professions and in their work-places (Coetzee, 2012). Paying attention to the graduateness of students prepares them for successful transition to work and managing their continued employability in a rapidly changing occupational world (Coetzee, 2012; Griesel \& Parker, 2009; Rothwell, Jewell, \& Hardie, 2009; Steur, Jansen, \& Hofman, 2012; Wendlandt \& Rochlen, 2011).

Seeing prospective and current employees' graduateness skills and attributes as being vital in creating the type of workplace culture in which innovation, adaptability and flexibility thrive (Thompson, Treleaven, Kamvounias, Beem, \& Hill, 2008; Van Dam, 2004), employers generally consider these generic, transferable skills and attri-butes as signifying an employee's employability and work readiness (Griesel \& Parker, 2009; Raftapoulous, Coetzee, \& Visser, 2009). Measures of the skills and attri-butes that underpin the graduateness of employees and prospective employees as dis-tanceeducation learners have, therefore, become important for employers, educators 
and individuals pursuing a career in a changing occupational world that demands graduate employability (Coetzee, 2012; Rigby et al., 2010; Tomlinson, 2007; Yorke \& Knight, 2007).

The objective of this study is to report on the development and validation of the Graduate Skills and Attributes Scale (GSAS) as a measure of adult students' graduate-ness in the economic and management sciences field. The research question for this endeavour was: can the theoretical framework on the eight core graduate skills and attri-butes identified by Coetzee (2012) be operationalised into a reliable and valid measure of students' graduateness?

\section{Theoretical framework for the development of the GSAS}

Graduateness refers to the quality of personal growth and intellectual development of the graduates produced by a higher education institution, and the relevance of the gra-duateness skills and attributes they bring to the workplace (Coetzee, 2012; Coetzee \& Schreuder, 2011; Coetzee \& Schreuder, 2012; Griesel \& Parker, 2009; Steur et al., 2012).

Based on an extensive review of the research literature, South African employer surveys and higher education academics' perceptions on student graduateness, Coetzee (2012) identified eight core skills and attributes that constitute the graduateness of students' pursuing a career in the economic and management sciences. These eight graduate skills and attributes are clustered in three holistic, overarching attitudinal domains of personal and intellectual development (Barrie, 2004; Coetzee, 2012; Coetzee \& Schreuder, 2012; Steur et al., 2012): scholarship, global and moral citizen-ship and lifelong learning.

\section{Scholarship}

Scholarship represents graduates' attitude or stance towards knowledge. As scholars, graduate employees should be leaders in the production and application of new knowl-edge and understanding through inquiry, critique and synthesis. They should be able to apply their knowledge to solving consequential and complex problems, and communi-cate their knowledge confidently and effectively. Coetzee (2012) identified three sets of skills that relate to graduates' scholarship: problem-solving and decision-making skills; analytical thinking skills and enterprising skills.

Problem-solving and decision-making skills relate to the ability to consider the complexities of the larger cultural, business and economic reality when approaching a problem or situation, and to initiate the necessary changes to ensure growth in personal and work life. It also includes the ability to be creative and proactive in problem solving; offering unique and novel ideas that add new knowledge and insights to a problem or situation; and the ability to make clear decisions that spur others on (Coetzee, 2012). Creative problem solving drives the business processes that facilitate innovation, flexibility and competitiveness (Yamoah, 2010) and demands critical think-ing and confidence in decision-making (Page \& Mukherjee, 2007). 
Analytical thinking skills involve higher-order critical or reflective thinking in giving accurate explanations of information and data, and making rational judgments from analysing information and data; breaking information into component parts to see relationships and patterns, and drawing insightful conclusions from numerical data (Coetzee, 2012).

Enterprising skills involve being venturesome and applying critical thinking, initiat-ive and proactivity when engaging in economic activities or undertakings, either to create and operate an enterprise of one's own or to be a substantial contributor to an enterprise as an employee. Being enterprising also means that one is able to recognise and be adept at dealing with organisational or team politics, have sound financial aware-ness and think in terms of profit, loss and added value when controlling costs and budgets. It also implies functioning in an autonomous, logical and disciplined manner when approaching problems or situations; considering the consequences of sol-utions by examining their feasibility, and weighing their impact within the larger cul-tural, business or economic reality (Coetzee, 2012). Finding ways of harnessing the creative energy, innovation and drive associated with employees' enterprising skills, and channelling these skills into endeavours consistent with organisational goals, out-comes and strategy may help serve as a catalyst for business and individual success and performance (Culbertson, Smith, \& Leiva, 2011).

\section{Global and moral citizenship}

Global and moral citizenship represents graduates' attitude or stance towards the world and their communities. As global and moral citizens, graduate employees must aspire to contribute to a global and local society in a full, meaningful, ethical and responsible way through their roles as members of local, national and global communities (Barrie, 2004; Steur et al., 2012). Coetzee (2012) identified three sets of skills that relate to the global and moral citizenship of graduates: ethical and responsible behav-iour, presenting and applying information skills, and interactive skills.

Demonstrating ethical and responsible behaviour implies that one accepts full responsibility for the results of one's decisions and actions, upholding the ethics and values of one's profession, community and/or workplace in all one does. It also implies that one is willing to take the lead in providing direction to others, motivating and empowering them to behave ethically towards the community and environment, and that one accepts full responsibility for the results of one's decisions and actions (Coetzee, 2012). Organisations and society at large recognise that ethically and socially responsible behaviour plays a crucial role in good business practices. They, therefore, increasingly demand that graduates be held accountable for understanding the impor-tance and consequences of the ethical and socially responsible behaviour relevant to their major studies and profession (Nicholson \& DeMoss, 2009).

Presenting and applying information skills imply that one is able to present (verb-ally or written) one's knowledge, facts, ideas and opinions clearly to convince one's audience, avoiding jargon or complicated language when presenting one's ideas or insights. One is able to commit information to memory quickly, and apply information to offer solutions for making a positive difference in one's personal life, community or workplace, and by considering a wide range of alternatives (Coetzee, 2012). Reissner (2010) regards critical thinking, reading and writing as the pillars of graduate studies, professional work, continued professional development and in all domains of the graduate's life. In organisations, individuals' success depends to a large extent on their ability to organise 
and present ideas confidently, to stay focused and to show enthusiasm and clarity (Watson \& Adamson, 2010). Well-developed critical thinking skills in presenting and applying information (written or orally) can be a powerful com-munication tool that helps to inform or persuade others, and contribute to graduates' success in the workplace (Watson \& Adamson, 2010). Cameron (2007) regards critical reading and writing as a transferable skill that enhances graduates' further studies and career progression.

Interactive skills relate to the effective and efficient use of language and technology when communicating and interacting with people from diverse cultures, backgrounds and authority levels and building social networks (Coetzee, 2012). Employers expect from graduates a good command of English as a major business language (Griesel \& Parker, 2009) and relevant knowledge and diversified social, communication and cooperation skills, the ability to work in different contexts with experts from other fields and the ability to critically select, acquire, use and produce new knowledge to the advantage of the business objectives (Tynjälä, 1999).

\section{Lifelong learning}

Lifelong learning relates to graduates' attitude or stance towards themselves. As lifelong learners, graduate employees must be committed to and capable of continuous learning in order to further their understanding of the world and their place in it (Barrie, 2004). Coetzee (2012) identified two sets of skills that relate to the global and moral citizenship of a graduate: goal-directed behaviour and continuous learning orientation.

Setting realistic goals, developing plans and taking action to achieve one's goals, accomplish tasks and meeting deadlines are core elements of goal-directed behaviour. Goal-directed behaviour also implies that one is able to access the information needed to solve problems or make decisions and surf the Internet to find new information (Coetzee, 2012). Bezuidenhout (2011) regards goal-directed behaviour as an important aspect of individuals' self-managed employability.

Graduates with a continuous learning orientation have developed a cognitive metaawareness and openness towards their own learning, a willingness to proactively engage in the process of acquiring new knowledge, skills and abilities throughout their lives and career in reaction to, and in anticipation of, changing technology and per-formance criteria (Coetzee, 2012). Reflecting on and reasoning about one's work develop the higher-level critical thinking skills that serve graduates well in any endea-vour (Celuch \& Slama, 1999; Reissner, 2010).

The theoretical framework of Coetzee (2012) on graduate skills and attributes compares well with international frameworks highlighting problem solving and decisionmaking, critical thinking, writing and speaking (communication skills), proficiency in English, team work, interpersonal skills, research skills, information literacy and ethical awareness as important generic graduate capabilities across various disciplines (Barrie, 2004; Dhiman, 2012; Faber, López, \& Prescher, 2012; Griesel \& Parker, 2009; McNeil et al., 2012; Spencer, Riddle, \& Knewstubb, 2012; Steur et al., 2012; Tynjälä, 1999; Velasco, 2012). 
Method

Based on the theoretical framework and operational definitions developed by Coetzee (2012), the researcher generated 80 items reflecting the various graduate skills and attributes outlined in the eight theoretical sub-dimensions identified by Coetzee (2012). A content analysis was then conducted involving two industrial psychologists and 10 academics in the economic and management sciences field (accounting, auditing and taxation, economics, industrial and organisational psychology, human resource management, business management, public administration and management, finance, risk management and banking, marketing and retail management) to ensure that the items reflected the eight theoretical sub-dimensions. A total of 16 items were removed due to redundancies which resulted in a 64-item pool for the research questionnaire. A web survey was used to collect the data. Participants responded to the questionnaire by indicating the extent to which they agreed or disagreed with each statement using a six-point Likert-type scale, ranging from one (strongly disagree) to six (strongly agree).

\section{Participants}

The participants for the scale development survey were a non-probability sample of adults employed in the South African service industry who were enrolled for further education studies at an open and distance-learning (ODL) higher education institution. The total sample of 272 comprised predominantly black $(85 \%)$ participants. The par-ticipants occupied relatively high-level positions at senior and middle-management levels (20\%) as well as middle- and first-level supervisory levels $(13 \%)$, and staff levels $(68 \%)$ in the South African service industry $(81 \%)$. Females represented $86 \%$ of the sample. Most of the participants $(72 \%)$ were in the early adulthood life stage (25-40 years) which is regarded as the exploration and establishment phases of their careers (Schein, 2006). In terms of level of academic study, $84 \%$ were final-year under-graduate students in the economic and management sciences field. Honours and post-graduate diploma levels comprised 9\%, master's level $6 \%$ and doctoral level $1 \%$ of the sample.

\section{Results}

The 64 items were subjected to a principal axis factor analysis with varimax rotation after evaluating the Kaiser-Meyer-Olkin measure of sampling adequacy (.91) and Bar-tlett's test of sphericity (approximate chi-square $=10,730.949 ; \mathrm{df}=2016 ; \mathrm{p}=$ $.000)$ values. Examination of the scree plot and factor interpretability revealed the presence of 8-15 plausible factors. As shown in Table 1, factors with item-factor loadings of $\geq .30$ were retained, revealing an eight-factor solution fitting the theoretical model proposed by Coetzee (2012). All 64 items were retained. Cronbach's alpha internal consistency coefficients ranged between .75 and .92 (Table 2). Inter-subscale corre-lations (Table 3) ranged between .46 and .86, suggesting acceptable construct validity (Bollen, 1989; Tabachnik \& Fidell, 2007) of the GSAS.

Study 2: GSAS validation

Method 
Table 2. Means, standard deviations and internal consistency reliability estimates for the GSAS in the development and validation samples.

\begin{tabular}{|c|c|c|c|c|c|c|}
\hline \multirow[b]{2}{*}{ Subscale } & \multicolumn{3}{|c|}{$\begin{array}{l}\text { Development sample } \\
\qquad(\mathrm{N}=272)\end{array}$} & \multicolumn{3}{|c|}{$\begin{array}{l}\text { Validation sample } \\
\qquad(\mathrm{N}=1102)\end{array}$} \\
\hline & M & SD & $\begin{array}{l}\text { Cronbach's } \\
\text { alpha }\end{array}$ & M & SD & $\begin{array}{l}\text { Cronbach's } \\
\text { alpha }\end{array}$ \\
\hline Interactive skills & 5.41 & 0.13 & .92 & 4.48 & 0.83 & 96 \\
\hline $\begin{array}{l}\text { Problem-solving/decision- } \\
\text { making skills }\end{array}$ & 5.33 & 0.15 & .86 & 4.28 & 0.86 & .89 \\
\hline Continuous learning orientation & 5.46 & 0.07 & .87 & 4.53 & 0.89 & .89 \\
\hline Enterprising skills & 5.21 & 0.13 & .86 & 4.17 & 0.87 & .88 \\
\hline $\begin{array}{l}\text { Presenting and applying } \\
\text { information skills }\end{array}$ & 5.28 & 0.09 & .78 & 4.36 & 0.89 & .96 \\
\hline Goal-directed behaviour & 5.25 & 0.36 & .87 & 4.40 & 0.83 & 79 \\
\hline $\begin{array}{l}\text { Ethical and responsible } \\
\text { behaviour }\end{array}$ & 5.43 & 0.13 & .75 & 4.76 & 0.90 & .80 \\
\hline Analytical thinking skills & 5.25 & 0.10 & .85 & 4.04 & 1.02 & .80 \\
\hline
\end{tabular}

\section{Participants}

A quantitative survey design was used whereby the GSAS was initially mailed to a stratified proportional random sample of 4850 undergraduate ODL adult students enrolled for further studies in the economic and management sciences field. The sample was stratified by module, qualification, department and school. The survey yielded 1102

useable questionnaires (response rate $=23 \%$ ). The participants comprised $92 \%$ black undergraduate students between 18 and 40 years (88\% early-career stage), $63 \%$ females and $57 \%$ employed. Participants responded to the questionnaire by indicating the extent to which they agreed or disagreed with each statement using a six-point Likert-type scale, ranging from one (strongly disagree) to six (strongly agree).

\section{Results}

Confirmatory factor analysis (CFA) showed that the data for the GSAS fit the baseline measurement model well, indicating construct validity. The fit indices were root-meansquare error of approximation $(\mathrm{RMSEA})=.053$, standardised root-mean-square residual $(\mathrm{SRMR})=.049$ and comparative fit index $(\mathrm{CFI})=.90$ (good fit), which is in line with established joint fit criteria (Hu \& Bentler, 1999; Kline, 2005). With the exception of the ethical and responsible behaviour dimension, the standardised factor loadings (shown in Table 1) were all significant and high (> .79). All the item loadings are moderate to strong (>.50->.70) indicators of the eight second-order constructs of the GSAS, which are, in turn, strong indicators of the overall graduateness skills and attributes construct. These results thus confirm the convergent validity of the GSAS.

To establish the intra-dimensional discriminant validity of the GSAS, the average variance extracted (AVE) estimates were compared with the squared interconstruct correlations (SIC) associated with each of the eight factors. The results shown in Table 4 show that the SIC values are mostly larger than the AVE values, indicating a lack of intra-dimensional discriminant validity. Sub-dimensions that seem to show acceptable discriminant validity are interactive skills versus ethical and responsible behaviour, continuous learning orientation versus ethical and responsible behaviour and analytical thinking skills, and ethical and responsible behaviour versus goal-directed behaviour. 
Table 1. GSAS definitions, eigenvalues, factor loadings and communalities.

Loadings (DS)

Factor/item

\begin{tabular}{|c|c|c|c|c|c|c|c|c|}
\hline \multicolumn{8}{|c|}{ Loadings (DS) } & \multirow{2}{*}{$\begin{array}{l}\text { Loadings } \\
\text { (VS) }\end{array}$} \\
\hline 1 & 2 & 3 & 4 & 5 & 6 & 7 & 8 & \\
\hline
\end{tabular}

Factor 1: Interactive skills (Use of English language and technology when communicating with others and personal efficacy in .89

communicating and interacting with people from diverse cultures, backgrounds and authority levels)

I can communicate my viewpoints with clarity and fluency in English

I find it easy to listen to and understand what others are saying

I find it easy to confront people's problems to resolve conflicts

I can use technology effectively to communicate with others

others

I can gain support from others for recommendations and ideas

I find it easy to persuade, convince or influence others

I find it easy to quickly gain respect from others

I usually show respect for the views and contributions of other team members

I usually make a favourable first impression

I find it easy to make clear, concise presentations to others

I find it easy to communicate effectively with people from different cultures, backgrounds and authority levels

I find it easy to get cooperation and support from others when working in a team

I consult others and share my expertise and information

I am able to build wide and effective networks of contacts to achieve my goals

I seek to progress to roles of increased responsibility and influence

$\begin{array}{ll}.6 & .71 \\ .5 & .62 \\ .61 & .72 \\ .69 & .64 \\ .37 & .6 \\ .57 & .76 \\ .52 & .63\end{array}$

Factor 2: Problem-solving and decision-making skills (Creativity and proactivity in the process of producing a solution to a recognised problem or problematic situation)

I make quick but clear decisions that spur others on towards action

I can probe for further information to enhance my understanding of a problem

I can structure information in a way that meets the needs of my audience

I can initiate changes to make my work or life more satisfying and developmental

I consider the complexities of the larger cultural, business and economic reality when approaching a problem or situation

$\begin{array}{ll}.51 & .5 \\ .6 & .64 \\ .53 & .68 \\ .65 & .63 \\ .62 & .66\end{array}$


I offer unique and novel ideas that add new knowledge and insights to a problem or

\section{situation}

I am creative in achieving my goals by anticipating problems before they happen

I usually set priorities with a proper sense of urgency and importance

Factor 3: Continuous learning orientation (Cognitive openness towards and awareness of, and proactive engagement in, the process of acquiring new knowledge, skills and abilities throughout one's life and career in reaction to, and in anticipation of, changing technology and performance criteria)

I follow up on goals, tasks and assignments to ensure successful completion

I monitor my performance against deadlines and milestones

I make sure that I keep myself up to date on technical knowledge and new

developments in my field

I am always on the lookout for ways to improve my knowledge and skills, and develop myself as a person

I know how to ask the right questions to get needed information and to properly size up a situation

I accept and tackle demanding goals with enthusiasm

I make use of developmental or training opportunities to enhance my competencies,

knowledge and skills

Factor 4: Enterprising skills (Venturesome application of critical reasoning, initiative and proactivity in engagement of economic activities or undertakings)

I prefer to work under my own direction

I can think in a disciplined and logical manner when approaching problems or

I consider the consequences of solutions by examining their feasibility and weighing 
Table 1. Continued.

Loadings (DS)

\begin{tabular}{|c|c|c|c|c|c|c|c|c|c|}
\hline \multirow[b]{2}{*}{ Factor/item } & & \multirow{2}{*}{$\begin{array}{l}\text { Loadings } \\
\text { (VS) }\end{array}$} \\
\hline & 1 & 2 & 3 & 4 & 5 & 6 & 7 & 8 & \\
\hline $\begin{array}{l}\text { When controlling costs and budgets, I usually think in terms of profit, loss and added } \\
\text { value }\end{array}$ & & & & .57 & & & & & .56 \\
\hline I find it easy to identify business opportunities for myself, my community or & & & & .55 & & & & & .55 \\
\hline
\end{tabular}

organisation

Factor 5: Presenting and applying information skills (Communicating knowledge, facts, ideas and opinions clearly and convincingly with a

view to offer solutions for one's personal benefit, or for the benefit of one's community or workplace

I can write my ideas and opinions clearly to convince my audience

I avoid using unnecessary jargon or complicated language when presenting my ideas

or insights

I find it easy to commit information to memory quickly

I consider a wide range of alternatives prior to making a decision

The solutions I offer make a positive difference in my personal life, community or workplace

Factor 6: Goal-directed behaviour (Proactivity and initiative in achieving one's goals, accomplishing tasks or meeting deadlines)

I spend a lot of time surfing the internet to find new information on search engines

I find it easy to access the information I need to solve problems or make decisions

I avoid jumping to premature conclusions

I try to find the real cause of problems before taking action

I usually set realistic goals

I take action to achieve my goals

I develop plans for specific goals and tasks

I use time efficiently

I find it easy to meet deadlines

$\begin{array}{ll}.75 & .55 \\ .6 & .55 \\ .46 & .53 \\ .49 & .63 \\ .47 & .65 \\ .72 & .64 \\ .58 & .72 \\ .61 & .63 \\ .55 & .53\end{array}$


Factor 7: Ethical and responsible behaviour (Responsible leadership in upholding the code of moral beliefs and values of one's profession, community and/or workplace in all one does

I accept responsibility for the results of my decisions and actions

I personally take the credit or blame for the results of my work

I uphold the ethics and values of my profession, community or workplace in all I do

I encourage responsible behaviour towards the community and the environment

I find it easy to provide direction to others, and to motivate and empower them

Factor 8: Analytical thinking skills (Skillful logical and critical reasoning and analysis in explaining information and data, and drawing insightful conclusions from the data analysis)

I feel confident in my ability to draw insightful conclusions from numerical data

I can break information into component parts to see relationships and patterns

I can make a rational judgment from analysing information and data

I can give accurate explanations of information and data presented to me

Eigen values

Percent common variance

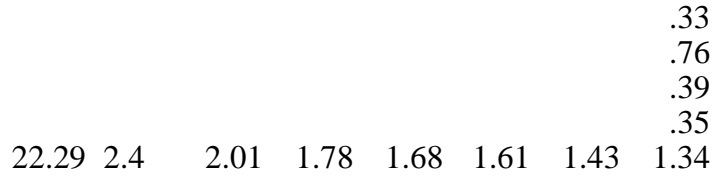

Notes: $N=272$. Boldface values identify the strongest item-factor loadings for each item. DS, loadings of development sample (exploratory factor analysis [EFA]); VS, standardised loadings of validation sample (CFA) all significant at $\mathrm{p}=.000$. 
Inter-subscale correlations (Table 3) ranged between .46 and .79, suggesting acceptable construct validity (Bollen, 1989; Tabachnik \& Fidell, 2007) of the GSAS. However, similar to the CFA results, the magnitude of the intercorrelations suggests that the items defining the eight sub-dimensions of the GSAS may possess excessive overlapping item content (i.e., a lack of discriminant validity among the sub-dimensions). 
Table 3. Correlations between the GSASs in the development and validation samples.

\begin{tabular}{|c|c|c|c|c|c|c|c|c|}
\hline & IS & PSDS & CLO & ES & PAIS & GDB & ERB & ATS \\
\hline Interactive skills & - & .64 & .79 & .76 & .60 & .69 & .45 & .56 \\
\hline Problem-solving/decision-making skills & .78 & - & .72 & .73 & .76 & .76 & .56 & .67 \\
\hline Continuous learning orientation & .72 & .83 & - & .70 & .64 & .76 & .42 & .53 \\
\hline Enterprising skills & .74 & .73 & .67 & - & .64 & .69 & .51 & .60 \\
\hline Presenting and applying information skills & .81 & .80 & .68 & .74 & - & .73 & .49 & .61 \\
\hline Goal-directed behaviour & .82 & .82 & .86 & .74 & .75 & - & .46 & .49 \\
\hline Ethical and responsible behaviour & .59 & .57 & .55 & .58 & .68 & .60 & - & .56 \\
\hline Analytical thinking skills & .67 & .71 & .59 & .64 & .72 & .65 & .46 & - \\
\hline
\end{tabular}

Notes: Correlations all significant at $\mathrm{p}=.000$. IS, interactive skills; PSDS, problem-solving and decision-making skills; CLO, continuous learning orientation; ES, enterprising skills; PAIS, presenting and applying information skills; GDB, goal-directed behaviour; ERB, ethical and responsible behaviour; ATS, analytical thinking skills. Correlations below the diagonal represent the development sample $(\mathrm{N}=272)$. Correlations above diagonal represent the validation sample $(\mathrm{N}=1102)$.

Table 4. AVE estimates for each GSAS factor vs. the SIC associated with the relevant factor (validation sample).

\begin{tabular}{|c|c|c|c|c|c|c|c|c|c|}
\hline & \multicolumn{9}{|c|}{ SIC } \\
\hline & AVE & IS & PSDS & CLO & ES & ERB & PAIS & GDB & ATS \\
\hline Interactive skills & 41 & - & .69 & .78 & .75 & .40 & .74 & .64 & .54 \\
\hline Problem-solving/decision-making skills & 42 & 69 & - & .79 & .79 & .53 & .99 & .84 & .72 \\
\hline Continuous learning orientation & .50 & .78 & .79 & - & 68 & .33 & .75 & .88 & .46 \\
\hline Enterprising skills & .37 & .75 & .79 & .68 & - & .45 & .80 & .61 & .63 \\
\hline Ethical and responsible behaviour & .33 & .40 & .53 & .33 & .45 & - & .49 & .32 & .46 \\
\hline Presenting and applying information skills & .35 & .74 & .99 & .75 & .80 & .49 & - & .84 & .75 \\
\hline Goal-directed behaviour & .39 & 64 & .84 & .88 & .61 & .32 & .84 & - & .47 \\
\hline Analytical thinking skills & .45 & .54 & .72 & .46 & .64 & .46 & .75 & .47. & - \\
\hline
\end{tabular}

Notes: IS, interactive skills; PSDS, problem-solving and decision-making skills; CLO, continuous learning orientation; ES, enterprising skills; PAIS, presenting and applying information skills; GDB, goal-directed behaviour; ERB, ethical and responsible behaviour; ATS, analytical thinking skills; AVE, average variance extracted and SIC, squared interconstruct correlations. 
Table 5. GSAS person and item statistics of validation sample.

\begin{tabular}{|c|c|c|c|c|c|c|}
\hline Dimension & Average Measure (SD) & Infit (SD) & Outfit (SD) & Separation & Reliability & $\alpha$ \\
\hline \multicolumn{7}{|c|}{ Interactive skills } \\
\hline Person & $0.91(1.09)$ & $1.03(0.74)$ & $1.03(0.73)$ & 3.05 & .90 & .96 \\
\hline Item & $0.00(0.29)$ & $1.00(0.15)$ & $1.02(0.19)$ & 8.56 & .99 & \\
\hline \multicolumn{7}{|c|}{ Problem-solving/decision-making skills } \\
\hline Person & $-1.14(1.44)$ & $0.99(0.82)$ & $0.98(0.81)$ & 2.00 & .69 & .89 \\
\hline Item & $0.00(0.23)$ & $1.00(0.14)$ & $0.99(0.15)$ & 6.64 & .98 & \\
\hline \multicolumn{7}{|c|}{ Continuous learning orientation } \\
\hline Person & $1.37(1.45)$ & $1.01(0.83)$ & $1.88(0.81)$ & 2.07 & .83 & .89 \\
\hline Item & $0.00(0.32)$ & $1.00(0.10)$ & $1.00(0.11)$ & 8.17 & .99 & \\
\hline \multicolumn{7}{|c|}{ Enterprising skills } \\
\hline Person & $-1.21(1.03)$ & $0.99(0.76)$ & $1.00(0.77)$ & 1.28 & 62 & .88 \\
\hline Item & $0.00(0.22)$ & $1.00(0.35)$ & $1.00(0.37)$ & 7.42 & .98 & \\
\hline \multicolumn{7}{|c|}{ Presenting and applying information skills } \\
\hline Person & $0.84(1.09)$ & $1.03(0.74)$ & $1.03(0.73)$ & 2.65 & .88 & .96 \\
\hline Item & $0.00(0.29)$ & $1.00(0.15)$ & $1.02(0.19)$ & 8.31 & .99 & \\
\hline \multicolumn{7}{|c|}{ Goal-directed behaviour } \\
\hline Person & $0.94(1.18)$ & $1.00(0.90)$ & $1.00(0.91)$ & 2.00 & .73 & .79 \\
\hline Item & $0.00(0.31)$ & $1.00(0.08)$ & $1.00(0.07)$ & 9.01 & .99 & \\
\hline \multicolumn{7}{|c|}{ Ethical and responsible behaviour } \\
\hline Person & $-1.59(1.55)$ & $0.91(0.80)$ & $0.90(0.80)$ & 1.18 & .58 & .80 \\
\hline Item & $0.00(0.21)$ & $1.01(0.18)$ & $0.91(0.15)$ & 6.45 & .98 & \\
\hline \multicolumn{7}{|c|}{ Analytical thinking skills } \\
\hline Person & $0.65(1.47)$ & $0.98(1.03)$ & $0.98(1.02)$ & 2.00 & .77 & .80 \\
\hline Item & $0.00(21)$ & $0.99(0.06)$ & $0.98(0.06)$ & 5.65 & .97 & \\
\hline \multicolumn{7}{|l|}{ Total scale } \\
\hline Person & $-2.03(81)$ & $1.05(0.62)$ & $1.05(0.61)$ & 5.03 & .96 & .98 \\
\hline Item & $0.00(31)$ & $1.01(0.29)$ & $1.04(0.34)$ & 10.11 & .99 & \\
\hline
\end{tabular}

To establish the usefulness of the GSAS, a Rasch analysis was performed. The Rasch analysis evaluated the unidimensionality of the GSAS by calculating the infit and outfit chi-square statistics to gain an indication of how well the items measure the underlying constructs. The results of the Rasch analysis further confirmed the reliability and construct validity of the GSAS. In terms of internal consistency reliability, Table 5 shows that all the GSAS dimensions obtained Cronbach's alpha coefficients which were higher than the guideline of .70 (Hair, Black, Babin, \& Ander-son, 2010). With the exception of the enterprising skills and ethical and responsible be-haviour sub-dimensions, the person separation statistics are in line with the guideline of $\geq 2.00$ (Bond \& Fox, 2007; Fox \& Jones, 1998). The item separation indices for all the dimensions are in line with the guideline ( $\geq 2.00$ ) (Bond \& Fox, 2007; Brand-Labuschagne, 2010; Fox \& Jones, 1998), indicating that the items of the sub-dimensions differentiate well among the measured variables and that the GSAS item placement could probably be replicated in other samples with confidence. These find-ings suggest that the GSAS could be regarded as a reliable and useful instrument.

The fit statistics (shown in Table 5) further confirm the unidimensionality and val-idity of the GSAS scale. Overall, Table 5 shows that the infit and outfit chi-square stat-istics for the person and item measures are equal to or close to 1.00 as suggested by Cervellione, Lee, and Bonnano (2009), confirming the construct validity and reliability of the GSAS subscale items and the GSAS as a measure of the graduateness skills and attributes construct. The items infit and outfit statistics were all $\leq 2.00$ which indicates 
that useful and logical information was obtained from the participants and that partici-pants in other settings will most probably provide the same answers. The person infit and outfit statistics indicate that the individual respondents responded to the items in a consistent manner.

\section{Discussion}

The results provided empirical evidence for the eight-factor theoretical framework postulated by Coetzee (2012) and confirmed the measurement accuracy, validity and usefulness of the GSAS as a measure of students' graduateness in the economic and management sciences field. Comparing the results of the present study to other similar international research data (Dhiman, 2012; Griesel \& Parker, 2009; McNeil et al., 2012; Spencer et al., 2012; Velasco, 2012) lies beyond the scope of this study but such a task could be considered an interesting contribution to the academic debate on measuring and assessing students' graduateness. Moreover, there seems to be a paucity of quantitative research on scales measuring the eight skills and attributes discussed in this paper. The uniqueness of the present study lies in the focus on measur-ing student graduateness as it applies to the economic and management sciences field by means of a pre-established theoretical framework (Coetzee, 2012). Research demon-strates that notions of developing and measuring graduate attributes succeed when they are conceptualised as integral to a disciplinary community and fit with the disciplinary and departmental culture (Jones, 2012; McNeil et al., 2012; Spencer et al., 2012). Measuring clearly defined graduate capabilities by means of an empirically validated theoretical framework in a specific disciplinary context enables the systematic develop-ment and evaluation of teaching, learning and assessment strategies aimed at develop-ing and assessing students' graduateness in a coherent and structured way at different levels of competency (Green, Hammer, \& Star, 2009; McNeil et al., 2012; Spencer et al., 2012). Problems of implementing the graduate skills and attributes agenda in higher education are generally attributed to the lack of a clear theoretical foundation and how these skills and attributes should be taught, assessed, measured and evaluated within a specific disciplinary context (Green et al., 2009).

The lack of intra-dimensional discriminant validity could be attributed to the fact that the eight dimensions of the GSAS assess very similar cognitive reasoning, critical thinking and problem-solving capacities relating to the intellectual development of a student. Green and colleagues (2009) also suggest that although it makes sense to deal with each identified graduate attribute as a separate component, it is important to recognise that different attributes tend to develop in relation to one another at different levels of competency and in accord with the conventions and norms of a specific discipline.

\section{Conclusion}

The present study added new knowledge to the extant literature on the skills and attri-butes that constitute a student's graduateness. It is trusted that the new insights gained from the results of this study will stimulate further research on the construct and measurement of graduateness. In the light of the empirical evidence provided in the present study, it is concluded that the eight-dimensional framework of Coetzee (2012) may serve as a useful guide for curriculum designers in establishing learning and assessment activities and approaches for cultivating the intellectual mindsets that 
signify the scholarship, citizenship and lifelong learning orientation of the student pur-suing a career in the economic and management sciences field (Coetzee, 2012). Beyond this, educators and learning and development practitioners need to consider how effec-tively the eight sets of skills and attributes might be developed within existing curricu-lum frameworks, how they will be assessed in terms of diverse groups of learners, to what extent and to what level students and employees already possess these skills and attributes, and whether or not teaching and training staff are competent to design teaching, learning and assessment strategies for developing these skills and attributes. By embedding the eight graduate skills and attributes in curriculum and course design, educators and learning designers could help cultivate the mindsets and skills embodied by a student's graduateness as important aspects of meeting the employability demands of employers.

\section{Limitations and recommendations for future research}

The present study has been limited to predominantly black and female early-career participants in the economic and management sciences field in a South African ODL higher education institution. Therefore, the findings cannot be generalised to other dis-ciplinary fields, educational, student, age, race or gender groups. Furthermore, due to the crosssectional design, causal relationships between the constructs could not be examined. Longitudinal research is recommended to substantiate the conclusions of the study and to investigate the GSAS dimensions over time in various educational, dis-ciplinary and occupational contexts. Ongoing data collection efforts will assist in pur-ifying the GSAS and improving its intra- and inter-discriminant validity. Such studies could also assess the predictive validity of the GSAS in terms of student employability and success in the workplace and assist in establishing norms for the GSAS and its sub-scales across different socio-demographic and occupational groups.

Notwithstanding the limitations pointed out, the GSAS shows promise as a tool for measuring, assessing and developing the graduate skills and attributes of adult learners. The study provides a valuable research framework for different disciplines to interpret and measure graduate skills and attributes in the context of their own epistemologies.

\section{Acknowledgement}

The author received financial support for the research, authorship and publication of this article from the University of South Africa.

\section{References}

Barrie, S.C. (2004). A research-based approach to generic graduate attributes policy. Higher Education Research \& Development, 23(3), 261-275.

Bezuidenhout, M. (2011). The development and evaluation of a measure of graduate employability in the context of the new world of work. Unpublished master's dissertation, University of Pretoria, Pretoria.

Bollen, K.A. (1989). Structural equations with latent variables. New York: John Wiley \& Sons.

Bond, T., \& Fox, C. (2007). Applying the Rasch model: Fundamental measurements in the human sciences (2nd ed.). Hillsdale, NJ: Erlbaum.

Brand-Labuschagne, L. (2010). Development and validation of new scales for psychological fitness and work characteristics of blue collar workers. Unpublished doctoral thesis, North-West University, Potchefstroom, South Africa.

Cameron, S. (2007). The business student's handbook (4th ed.). Harlow: Pearson. 
Celuch, K., \& Slama, M. (1999). Teaching critical skills for the 21st century: An advertising principles case study. Journal of Education for Business, 74(3), 134-139.

Cervellione, K.L., Lee, Y., \& Bonnano, G.A. (2009). Rasch modeling of the self-deception scale of the balanced inventory of desirable responding. Educational and Psychological Measurement, 69(3), 438-458.

Coetzee, M. (2012). A framework for developing student graduateness and employability in the economic and management sciences at the University of South Africa. In M. Coetzee, J. Botha, N. Eccles, N. Holtzhausen, \& H. Nienaber (Eds.), Developing student graduateness and employability: Issues, provocations, theory and practical guidelines (pp. 119-152). Randburg: Knowres.

Coetzee, M., \& Schreuder, A.M.G. (2011). The relation between career anchors, emotional intel-ligence and employability satisfaction among workers in the service industry. Southern African Business Review, 15(3), 76-97.

Coetzee, M., \& Schreuder, A.M.G. (2012, July). Employees' graduate and employability attributes in relation to their emotional intelligence and career anchors. Poster presented at the 30th international congress of psychology, Cape Town, South Africa.

Culbertson, S.S., Smith, M.R., \& Leiva, P.I. (2011). Enhancing entrepreneurship: The role of goal orientation and self-efficacy. Journal of Career Assessment, 19(2), 115-129.

Dhiman, M.C. (2012). Employers' perceptions about tourism management employability skills. Anatolia: An International Journal of Tourism and Hospitality Research, 23(3), 359-372.

Faber, K., López, V., \& Prescher, T. (2012). 'i-learn': Developing a new approach in higher edu-cation for lifelong learning. European Journal of Higher Education, 2(2-3), 218-233.

Fox, C., \& Jones, J. (1998). Uses of the Rasch modeling in counseling psychology research. Journal of Counseling Psychology, 45(1), 30-45.

Green, W., Hammer, S., \& Star, C. (2009). Facing up to the challenge: Why is it so hard to develop graduate attributes? Higher Education Research \& Development, 28(1), 17-29.

Griesel, H., \& Parker, B. (2009). Graduate attributes: A baseline study on South African gradu-ates from the perspective of employers. Pretoria: Higher Education South Africa and South African Qualifications Authority.

Hair, J.F. Jr., Black, W.C., Babin, B.J., \& Anderson, R.E. (2010). Multivariate data analysis (7th ed.). Upper Saddle River, NJ: Prentice Hall.

Hu, L.T., \& Bentler, P.M. (1999). Cutoff criteria for fit indexes in covariance structure analysis: Conventional criteria versus new alternatives. Structural Equation Modeling, 6(1), 1-55.

Jones, A. (2012). There is nothing generic about graduate attributes: Unpacking the scope of context. Journal of Further and Higher Education, 37(5), 591-605.

Kember, D., \& Leung, D.Y.P. (2005). The influence of active learning experiences on the devel-opment of graduate capabilities. Studies in Higher Education, 30(2), 155-170.

Kline, R.B. (2005). Principles and practice of structural equation modeling (2nd ed.). New York: Guilford Press.

Lo, P. (2011, August). The gap between teaching and learning in higher education: A crossdis-ciplinary study of learning style and teaching style in Taiwan. Paper presented at the American Psychological Association Convention. Washinton, DC, USA.

McNeil, H.P., Scicluna, H.A., Boyle, P., Grimm, M.C., Gibson, K.A., \& Jones, P.D. (2012). Successful development of generic capabilities in an undergraduate medical education program. Higher Education Research \& Development, 31(4), 525-539.

Nicholson, C.Y., \& DeMoss, M. (2009). Teaching ethics and social responsibility: An evaluation of undergraduate business education at the discipline level. Journal of Education for Business, 84(4), 213-218.

Page, D., \& Mukherjee, A. (2007). Promoting critical-thinking skills by using negotiation exer-cises. Journal of Education for Business, 82(5), 251-257.

Pityana, B. (2009). Keynote speech delivered at 23rd ICDE world conference on Open Learning and Distance Education, The Netherlands.

Raftapoulous, M., Coetzee, S.C., \& Visser, D. (2009). Work-readiness skills in the FASSET sector. SA Journal of Human Resource Management, 7(1), Art. no. 196. doi:10.4102/ sajhrm.v7i1.196

Reissner, S.C. (2010). Essential post-graduate study skills. In G. Watson \& C. Reissner (Eds.), Developing skills for business leadership (pp. 35-64). London: CIPD. 
Reissner, S.C., \& Watson, G. (2010). Skills for continuing professional development and prac-tice. In G. Watson \& C. Reissner (Eds.), Developing skills for business leadership (pp. 3-32). London: CIPD.

Rigby, B., Wood, L., Clark-Murphy, M., Daly, A., Dixon, P., Kavanagh, M., et al. (2010). The assessment of graduate skills: Orienting students and standards for an uncertain future. Australian Learning \& Teaching Council Project: Embedding the development and grading of generic skills across the business curriculum. Retrieved March 27, 2011, from http://www.graduateskills.edu.au/literature-review/

Rothwell, A., Jewell, S., \& Hardie, M. (2009). Self-perceived employability: Investigating the responses of post-graduate students. Journal of Vocational Behaviour, 75(2), 152-161.

Schein, E.H. (2006). Career anchors self-assessment (3rd ed.). San Francisco, CA: Pfeiffer.

Spencer, D., Riddle, M., \& Knewstubb, B. (2012). Curriculum mapping to embed graduate capabilities. Higher Education Research \& Development, 31(2), 217-231.

Steur, J.M., Jansen, E.P.W.A., \& Hofman, W.H.A. (2012). Graduateness: An empirical examination of the formative function of university education. Higher Education, 64(6), 861-874.

Tabachnick, B.G., \& Fidell, L.S. (2007). Using multivariate statistics (5th ed.). New York: Allyn \& Bacon.

Thompson, D., Treleaven, L., Kamvounias, P., Beem, B., \& Hill, E. (2008). Integrating graduate attributes with assessment criteria in business education: Using an online assessment system. Journal of University Teaching \& Learning Practice, 5(1), 1-14.

Tomlinson, M. (2007). Graduate employability and student attitudes and orientations to the labour market. Journal of Education and Work, 20(4), 285-304.

Tynjälä, P. (1999). Towards expert knowledge? A comparison between constructivist and a traditional learning environment in the university - The role of computer-based environments. International Journal of Educational Research, 31(5), 357-442.

Van Dam, K. (2004). Antecedents and consequences of employability orientation. European Journal of Work and Organizational Psychology, 13(1), 29-51.

Velasco, M.S. (2012). More than just good grades: Candidates' perceptions about the skills and attributes employers seek in new graduates. Journal of Business Economics and Management, 13(3), 499-517.

Watson, G., \& Adamson, I. (2010). Effective team-building and communication. In G. Watson \& C. Reissner (Eds.), Developing skills for business leadership (pp. 161-187). London: CIPD.

Wendlandt, N.M., \& Rochlen, A.B. (2008). Addressing the college-to-work transition: Implications for university career counsellors. Journal of Career Development, 35(2), 151-165.

Yamoah, F. (2010). Effective decision-making and creative problem-solving. In G. Watson \& C. Reissner (Eds.), Developing skills for business leadership (pp. 417-448). London: CIPD.

Yorke, M., \& Knight, P. (2007). Evidence-informed pedagogy and the enhancement of student employability. Teaching in Higher Education, 12(2), 157-170. 